\title{
SPC-Based Decision Supporting System For Data Analysis of Tomato, Bell Pepper and Chili
}

\author{
Zaira P. Caranay ${ }^{1}$ and Rionel Belen Caldo ${ }^{2, *}$ \\ ${ }^{1}$ Computer Engineering Department, Lyceum of the Philippines University - \\ Laguna (LPU-L), Philippines \\ ${ }^{2}$ Computer Engineering Department, Tanauan City College (TCC), \\ Batangas, Philippines \\ ${ }^{2}$ Electronics and Communications Engineering Department, \\ De La Salle University (DLSU), Manila, Philippines \\ E-Mail:rionel14_caldo@yahoo.com \\ ${ }^{*}$ Corresponding Author
}

Received 1 December 2016; Accepted 22 July 2017;

Publication 7 August 2017

\begin{abstract}
Indeed, Philippines is rich in agricultural resources. However, the country needs improvement by implementing new systems, which will help farmers in lessening their works. In this work, the proponents designed and developed a system that is capable of reading a excel file from the monitored plants (Bell pepper, Tomato and Chili). This study is divided in two parts; the software and the hardware. In hardware part, the proponents used LCD (Liquid Crystal Display) Monitor and cell phones. On the other hand, software parts included all the programming language like Visual Basic. Net. Decision Supporting System and Statistical Process Control (SPC) are the tools and methodologies used in this study. Moreover, control charts were used in showing data trends for analysis and make decision based on the data uploaded in the system. After analyzing of data, the design system will decide whether the charts encounters abnormality, Out-of-Control and Out-of-Specification, and it will be sent through text message. An SMS message will help the user to alert if there's an Out-of-Control and Out-of-Specification detected in the data.
\end{abstract}

Journal of Industrial Engineering and Management Science, Vol. 1, 123-148.

doi: 10.13052/jiems2446-1822.2017.006

(c) 2017 River Publishers. All rights reserved. 
With this, the module is able to help farmers in modeling an intelligent farm system with decision support system in identifying the special cause of variation of plants.

Keywords: Statistical Process Control, Control Charts, OOC, OOS and Decision Support System.

\section{Introduction}

\subsection{Background of the Study}

Technology has become part of one's lifestyle. It has been using so much, these days, in each, and in every domain of our lives, in education, business, agriculture, or in the regular household work and its uses are increasing day by day [1]. The enhancement in technology significantly affects different institutions, and the society in general, that created countless opportunities and challenges for millions of individuals and organizations. Like machines that are used to replace the work intended for humans primarily to reduce or lessen man power and also reduce human error [2]. Computers, gadgets and electronic equipment are used in daily basis, for example; researching in the earlier year is an arduous and time-consuming work. However, with the evolving technology, research literally can now be done with just a click and only in few minutes.

One of the big and possible roles of technology is the developing of new system for agricultural industry. Agriculture, such as farming is being generated in different countries in lessening farmers' work [3]. Philippines, indeed, is still mainly an agriculture country [4]. As a developing country, usually monitoring, gathering, analyzing of data and giving proper solutions to the vegetable crops are handled by the farmers manually, which give hassles to the farmers and results in the slow process [5]. In the field of farm, it is very unlucky that technology is not even sufficiently perceived such as management system. As a simple and new farmer, it would be very hard to decide whether what solution would fit the best for a vegetable crop. And also, the time that it consumes for the farmers and users analyze the conditions of the plants. Thus, this study aims for the solution of problem. This system will help to determine if there are patterns of abnormalities in data that causes to an unhealthy production of plants.

The proponents deemed that it is necessary to implement a system for notifying if there's some abnormalities encountered by the plants. The design 
system will help ease decision making for the farmer. Manual operation in the agriculture, such as roaming around the farm, and telling others what should be the action in maintaining healthy yield and productivity of the plants is greatly noticed by the developer, thus, the proponents decided to change the old way system by implementing new system. The development of new systems is important for determining the future agriculture.

In due course, the study relates on allowing today's farmers with different decision tools and measurement technologies aimed for incorporating items, information and administrations for better efficiency, quality and benefit. The system includes managing, storing, analyzing and decision for the vegetable crops with the used of different monitored parameters. It aims to help the farmers and users in lessening the time and effort that they needed to exert in the agriculture and farms. Additionally, it may help to maintain the quality of vegetable crops as it helps to monitor the plant. It is convenient to use, time saving and labor reduction for the farmers. For this study, the proponent gives an approach by using Visual Basic.Net, Microsoft Access for the database, Decision Support System and Statistical Process Control. This will help the user to monitor and analyze data, decision making and notify the user whether there's OOS and OSS detected; thus, this shows the difference of our system.

\subsection{Objectives of the Study}

This study aims to develop a database system that will help the users and farmers analyze data and decision making to analyze whether the plant encounters some abnormalities.

Specifically, the study aims to:

1. Design a user-friendly system which allows monitoring (LCD Monitor) of data and read an Excel file containing data from monitored vegetable crops such as Tomato, Chinese cabbage and Bell Pepper with different used parameters (Temperature, Humidity, Soil Moisture and pH Level) manage it effectively and use it to analyze its own activity;

2. Identify pattern with the use of Statistical Control Process and provide decision making based on the pattern;

3. Notify the user by sending a Short Message Service (SMS) with the problem encountered by the plants;

4. Test and evaluate the system and application in terms of functionality and accuracy. 


\subsection{Significance of the Study}

Modernization is being able to adjust to the most recent and current trend in innovation to enhance the quality of plants in the farm. The implementation of the system will greatly affect farmers and users since it can be aid in the uplifting of technological capability of the agriculture system. Thus, the farmers will not exert much time and effort, and better than doing things manually. System will provide the necessary features for the farming process such as decision making. It will automate the manual task that is being used in old process.

Additionally, the proponents will also be benefited from this study because they will be able to acquire deep knowledge that will largely help them when they become professional. By conducting this study, it will give them an opportunity to strengthen and practice their creativity and ability.

The system differs from the other system, since the most of the study such as Decision Supporting System didn't include Statistical Process Control. What makes the proponents system unique is the utilization of Statistical Process Control with the Decision Support System in analyzing whether the plants encounter an OOC or an OOS; it is integrated to come up with one system. It has the capability of reading a file such as Excel which consists of the data that is needed in analyze, and sending of SMS message containing the abnormality (OOC and OOS) found in the plants. Thus, this study is to help farmers minimize their effort in analyzing data. The system will be placed in a personal computers or laptops, because it will be used by the user, farmer or the administrator.

\subsection{Realistic Constraints}

1. Economics - The constraint when it comes to economic is the budget allotted to the project. The researchers allotted Php 4,000.00 for developing the system but the researchers spend almost Php 5,100.00 in completing the project. The user must buy an API Code monthly for the SMS notification, so it can send message to the farmer/user. The design of the system for use requires maintenance cost for continuously use of the system. The Solution to this problem is to make a Simple System which has the characteristics to improve from further study.

2. Environmental - The environmental constraints include weather and temperature. The system must be able to function perfectly in extreme weather and temperature and must not breakdown when the temperature and weather is bad. Since the extended monitor for the system is placed 
outside the tent, there is a strong possibility that it would be affected by the weather and temperature, so the solution must be the place should have a big roof to protect the LCD Monitor.

3. Manufacturability - Considering manufacturability the researchers have taken into account the possibility of future re-production. If the system were to be manufactured for a farm or in agriculture, the system must be made custom to fit the needs of the user/farmer. The system should be manufactured for the farmers who want to monitor the quality of the data of the plants. Also, the system should be adaptable for any of circumstances in order to use it effectively and be able to sell in the market.

4. Ethical - The researchers have considered ethical aspects for this dissertation. Proponents give more focus on legal aspect. Giving credits and citing of sources and other references used. The system should be safe for all the people; it should be made considering the safety and health of the users and the farmers. The system must be made and protect its patent so no one can make a copy of the system and maintain its originality.

5. Health and Safety - The system must always be safe not only for user/farmers to use, but also for the people around the system's placement. It should not raise an injury to any client's surrounding peers. Because the device needs electric, it should not be capable of producing any form of electric shock under any circumstance. The system, which is placed in the laptop should not over heat or become extremely hot because laptop can be damage and can cause injury because of electrical wirings inside the laptop. With this, the system must be placed in a safe area which will not produce danger to the user/farmer.

\section{Review of Related Literatures}

\subsection{Synthesis of Related Litaratures}

Based on the review of the related literature, due to evolution of technology there are different systems developed to help the users lessen their work. According to the review of related literature, there are different methods and techniques in designing and implementing the system. Most of the study conducted and implemented cited the used of sensors, GSM and smartphones in monitoring different parameters within the crops, plants, vegetable and surroundings, the data sensed by the sensors will be analyze and will be sent via SMS text messages. Additionally, most of the studies cited uses Web-based 
in viewing and accessing the information in through the use of internet. The used of .net platforms are also seen by the proponents to produce a graphical user interface. Thus, the used of different methods and technologies can be beneficial to provide an efficient and functional systems. Similarly, the used of smartphone and net will be used by the proponents in developing the system, but not the use of internet in viewing and accessing the data collected. Existing studies focuses more on monitoring and analyzing the data using internet, however their system is not capable of reading text file such as Excel, with this, the proponents' system came up of doing a study that enables system Excel file containing the monitored data.

\section{Conceptual and Theoretical Framework}

\subsection{Conceptual Framework}

The study aimed to design and develop a SPC-based decision support system for notifying and sending SMS message containing the detected occurrences found in the charts. In this study, the proponents were able to create diagrams showing the comprehensive order procedure on how the system will be done. With the use of diagrams, the proponents were capable of determining the things and tools needed in doing the study. In addition, it helps the proponents in forming the idea of processing the whole system.

The Figure 1 shows the method of research needed to follow to finish the system. First is the Topic Conceptualization, the proponents formulated an idea to be studied, and that idea came up in developing the study which is "SPC-Based Decision Supporting System for Data Analysis of Tomato, Bell pepper and Chili". Next is Problem Identification and Objective, this step is to identify the problem and specify the goals in making the system. As the proponents of this study, the observed problem is the manual operation in a Smart Farm. The third one is the Review of Related Literature and Synthesis, this means that the proponents needed to make research which is related to the study as well as summarizing the Related Literature to see the methods used in developing a system as well as to providing what makes the system unique by using different methods and enhancing some old systems. The fourth one is the Research Methodologies, in this step, the proponents must show the different framework of the system as well as the methods that they are going to use in designing the system. The fifth is the Design of SPC-Based Decision Supporting System for Data Analysis of Tomato, Bell Pepper and Chili, in the design; it will be composed of Database Management System, 


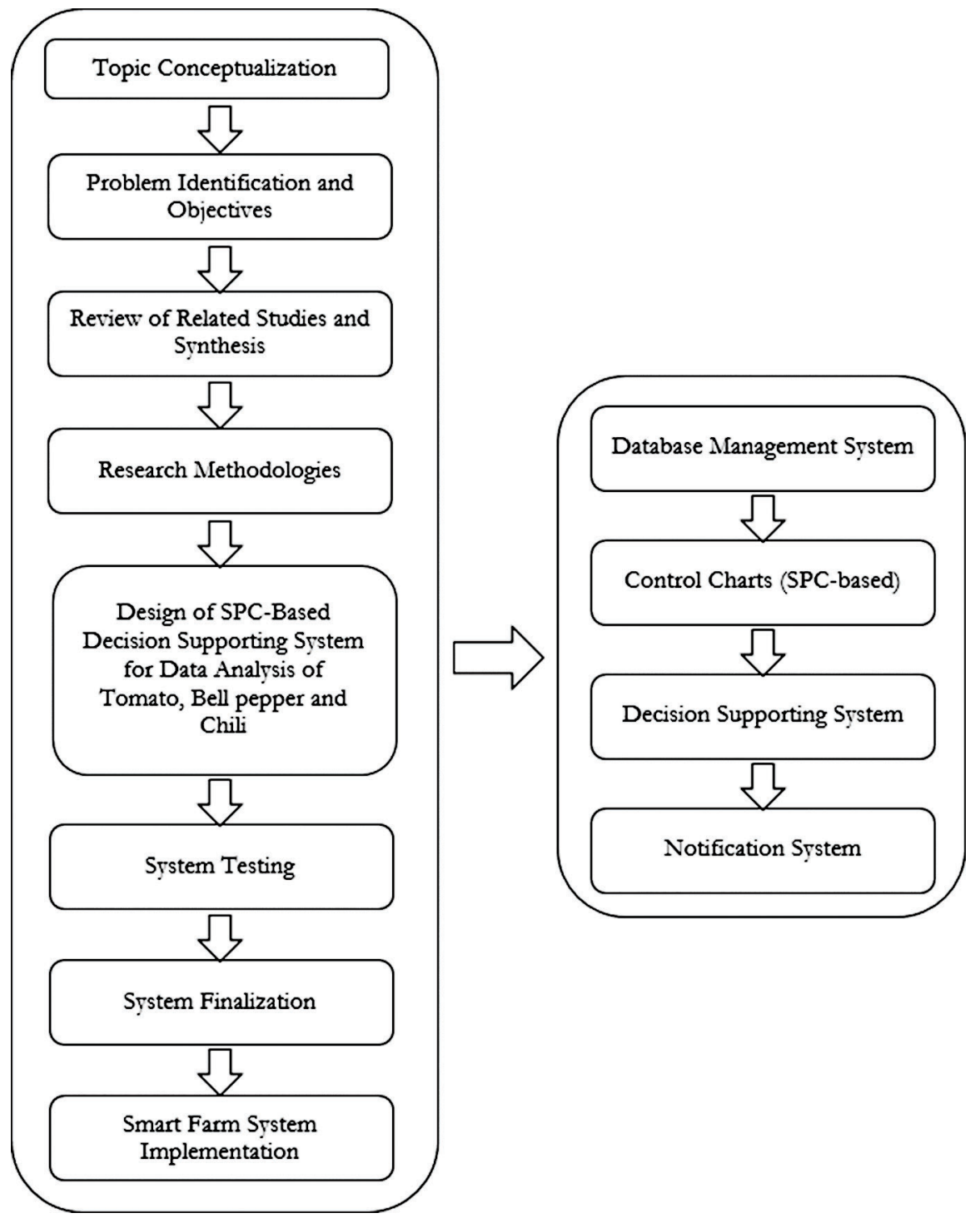

Figure 1 Method of research.

followed by Controlled Charts, then Decision Supporting System and the Notification System. The System Testing comes next, the proponents needed to test the system to see if there's a defect and if the system is producing an accurate and reliable outputs. Then System Finalization comes, this is where 

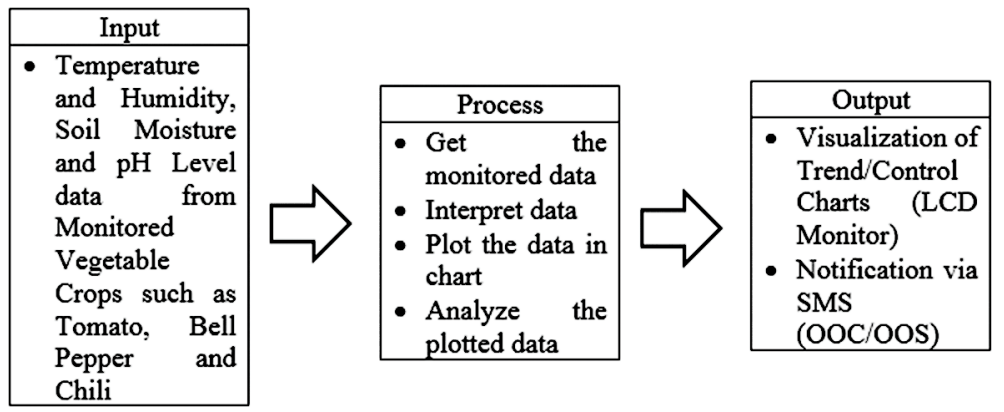

Figure 2 IPO chart.

the proponents need to finalize the system to be able to utilize by the user. Lastly is the Smart Farm System Implementation, the system must be implemented so that farmers will be able to use it to lessen their work.

The Figure 3 shows the flow of data in the whole system. The diagram is composed of Monitored Data from vegetable crops, Database Management, Statistical Process Control, Decision Support System, Notification and Short Message Service.

The monitored data from the monitoring system of the other group will be uploaded in the system, which is made up of Visual Basic. The monitored data will be plotted in the Statistical Process Control (Control Charts) to see the variation and trends of the input data. The Control Charts has its corresponding limits, with this, the system was able to see the occurring problems from the data. The abnormalities such as OOS and OOC in the data will be detected using the Decision Supporting System. The detected abnormalities made by Decision Making will be notified to the users through Short Message Service (SMS) as well as displaying of Control Charts in LCD Monitor.

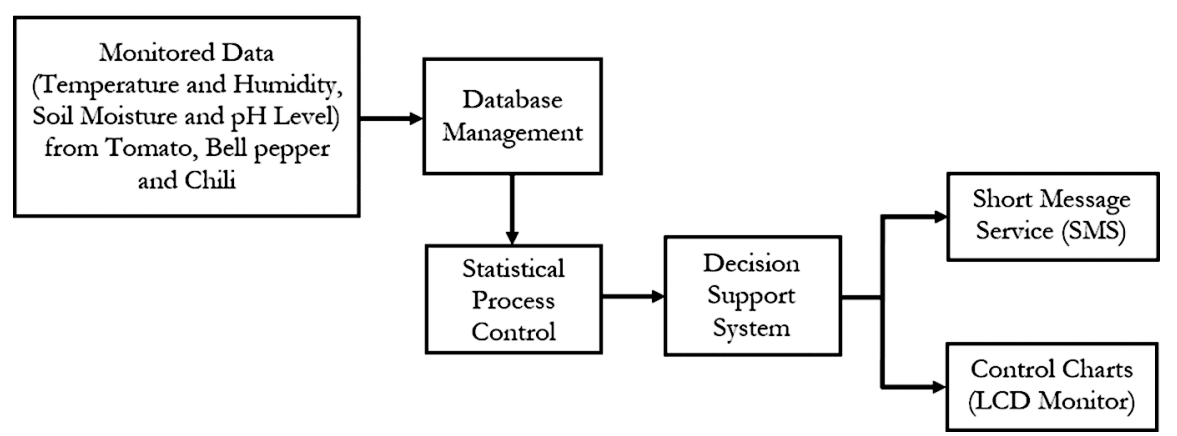

Figure 3 Block diagram of the system. 


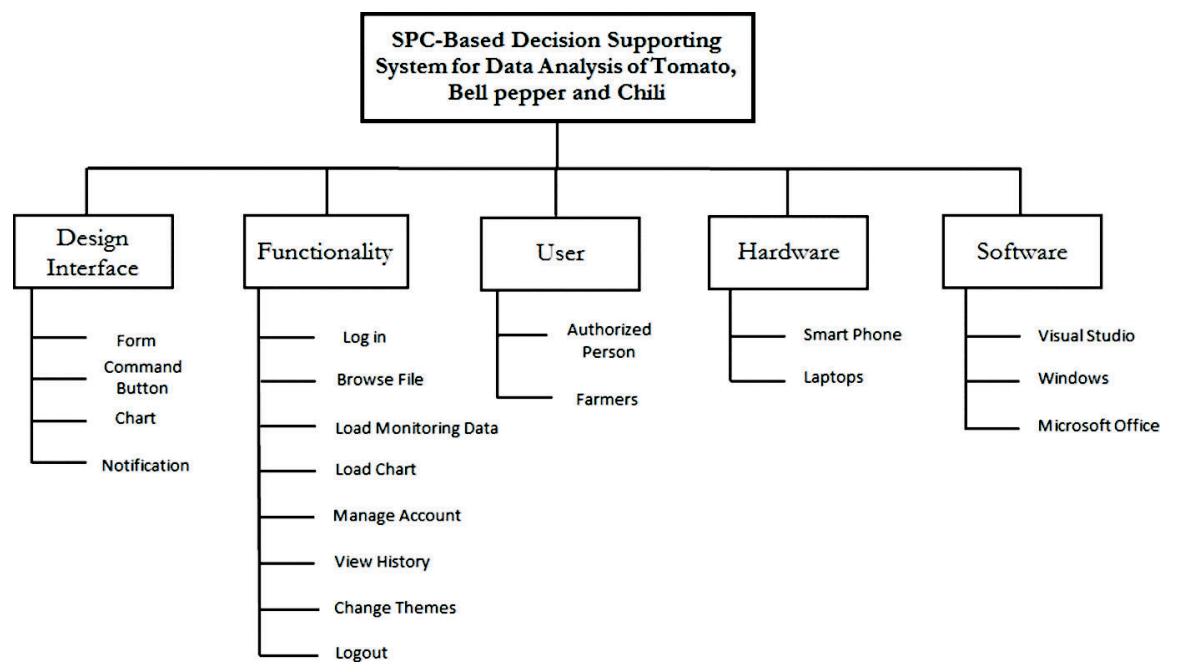

Figure 4 Work breakdown stucture (organizational chart).

The Work Breakdown Structure which is Figure 4 is divided into 5 segments which are the Design Interface, Functionality, User, Hardware and Software. For the Design Interface, it includes all the tools needed to design the Graphical User Interface. The Functionality describes the functions of the system that the user can do. The user talks about the people who can use the system. For the hardware, it simply describes the hardware part in the system and the Software part will be the software that will be used to design and develop the system. The Work Breakdown Structure which is Figure 5 is divided into 5 segments which are the Design Interface, Functionality, User, Hardware and Software. For the Design Interface, it includes all the tools needed to design the Graphical User Interface. The Functionality describes the functions of the system that the user can do. The user talks about the people who can use the system. For the hardware, it simply describes the hardware part in the system and the Software part will be the software that will be used to design and develop the system.

\subsection{Theoretical Framework}

\subsubsection{Statistical process control}

Dr. Walter Shewhart and Dr. W. Edwards Deming developed the concept and principle of Statistical Process Control [6]. Statistical Process Control produces Control Charts where it will show problems existing in the data. 


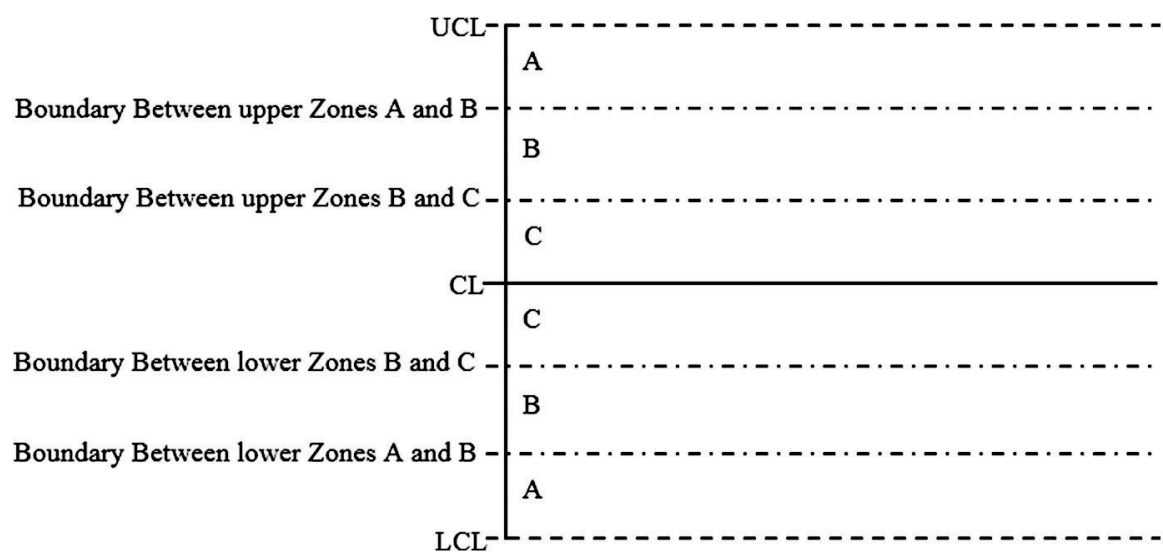

Figure 5 Designation of the computed values.

Out-of-Control conditions in the data will be shown using Control Charts [7]. It will be employ in the system to help farmers monitor and identify what should be the action need to be undertaken. The main objective of the SPC is to provide a real-time process to have a quality data and improve data constantly [8]. The collected data from the monitored vegetable crops will be uploaded in the system and the system will be plotting the data. With SPC concept, it will help users to maintain the quality of a product or process specifically vegetable crops that is being monitored and improved it by showing trends of data with the used of Control Charts for Variables. Charts are useful tool to monitor the data. Moreover, there are set limits and it is designed to recognize if a failure is occurring [9]. The data is arranged and plotted in a graph with a given limits to show the trends of data. Thus, the limits are used to recognize and correct the problems.

Equation used to show trends of data:

$$
\bar{X}=\frac{\text { Summation in a Row }}{\text { Number of Subgroups }}
$$

Range $=$ Highest Value in a row - lowest value in a row

$$
\begin{aligned}
\overline{\bar{X}} & =\frac{\text { Summation of } \overline{\mathrm{X}}}{\text { Number of observation }} \\
\bar{R} & =\frac{\text { Summation of Range }}{\text { Number of observation }}
\end{aligned}
$$




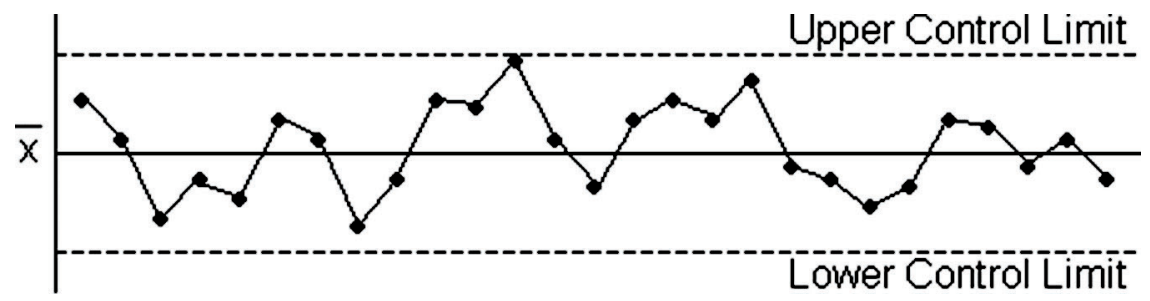

Figure 6 Process in control.

For X Bar Chart:

$$
\begin{aligned}
& \text { Upper Control Limit for } \bar{X}=\overline{\bar{X}}+\left[\left(A_{2}\right)(\bar{R})\right] \\
& \text { Lower Control Limit for } \bar{X}=\overline{\bar{X}}-\left[\left(A_{2}\right)(\bar{R})\right]
\end{aligned}
$$

Values for computing the subgroups:

$$
A_{2}=1.02
$$

Computation for Zones:

$$
\begin{aligned}
& \text { Boundary Between lower Zones A and B }=\overline{\bar{X}}-\left[\left(\frac{2}{3}\right)\left(A_{2}\right)(\bar{R})\right] \\
& \text { Boundary Between lower Zones B and } \mathrm{C}=\overline{\bar{X}}-\left[\left(\frac{1}{3}\right)\left(A_{2}\right)(\bar{R})\right] \\
& \text { Boundary Between upper Zones B and C }=\overline{\bar{X}}+\left[\left(\frac{1}{3}\right)\left(A_{2}\right)(\bar{R})\right] \\
& \text { Boundary Between upper Zones A and B }=\overline{\bar{X}}+\left[\left(\frac{2}{3}\right)\left(A_{2}\right)(\bar{R})\right]
\end{aligned}
$$

In determining the occurrences in the Control Chart, the data or point which will fall outside its control limit is the Process-Out of Control. Below are the following guidelines in determining the unexpected behavioral of the data:

1. For 9 or more continuing points below or above the central line it is considered unnatural. 


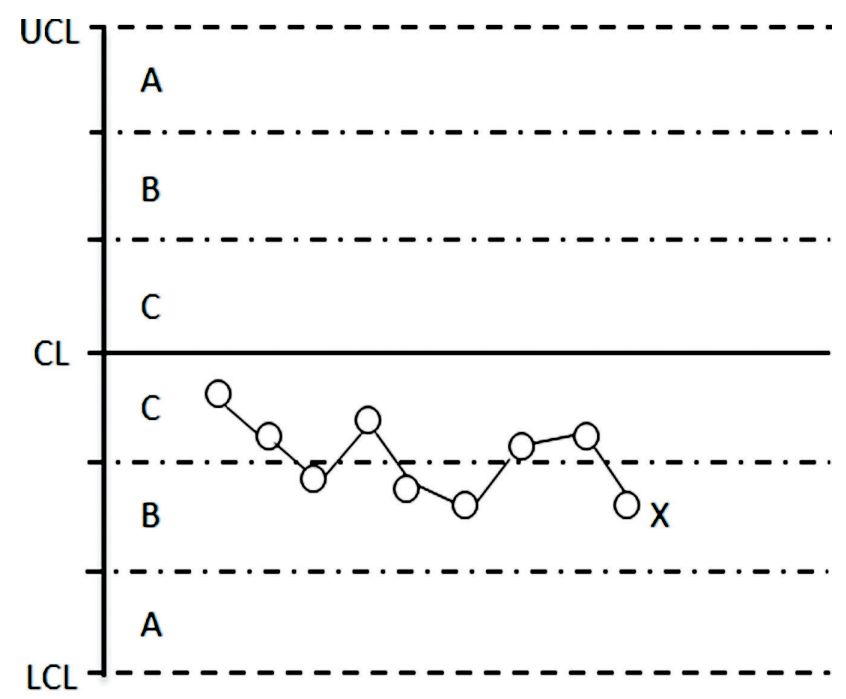

Figure 7 Nine consecutive points.

2. When point plotted beyond UCL or below LCL.

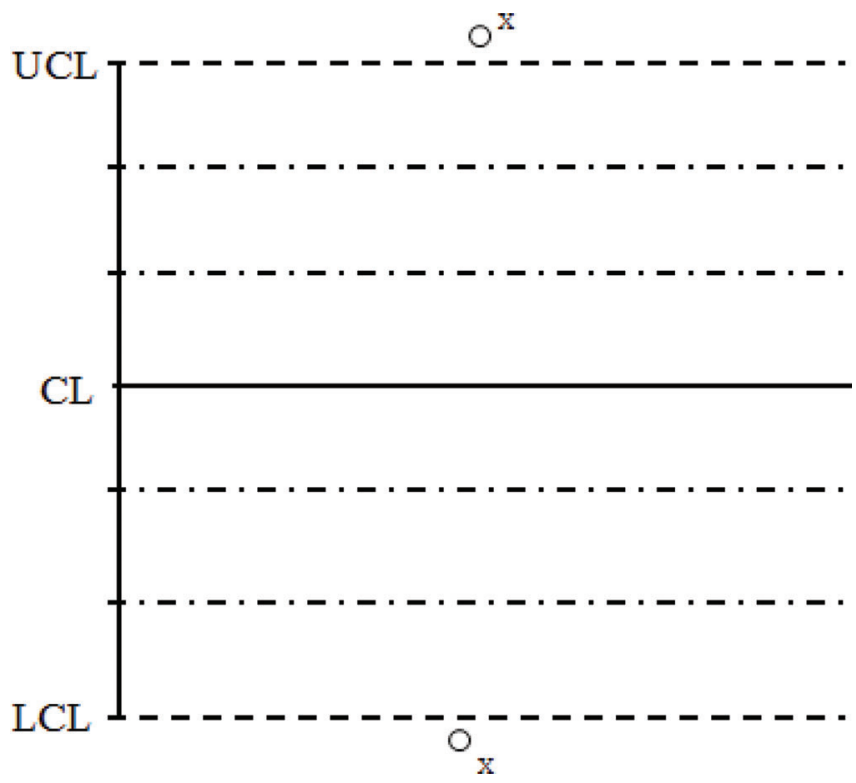

Figure 8 Point beyond UCL or LCL. 
The Out-of-Specification will be detected, once a data will fall out from the USL or in the LSL. USL and LSL is a user define value, the user will be the one who will enter the value needed by the plant.

\subsection{Plants and Its Behavior}

In this study, the researches focus mainly on three vegetable crops to be analyzed, these are the following:

- Tomato - Basically, tomato is served and consider as a vegetable and most people doesn't consider it as a fruit. Tomato is a fruit and part of potatoes and eggplants family. It comes in a variety of shapes, sizes and colors [10]. The ideal temperature for the tomato plant to grow is at $20-30^{\circ} \mathrm{C}$. For young plants to grow well in day and night, the temperature must be around $25^{\circ} \mathrm{C}$, but when it grows older, it seems to have an advantage from lower night than day temperature. To maintain fruit setting for tomato, it requires minimum growth temperature from $13-14.5^{\circ} \mathrm{C}$, for optimum growth it requires $15-20^{\circ} \mathrm{C}$, and for maximum growth temperature $22^{\circ} \mathrm{C}$, thus for marinating the fruit set tomato it requires $13-22^{\circ} \mathrm{C}$. Lower temperatures are required for tomatoes that are about to produce fruit in order for the fruit to express a more vibrant red color once it ripens $[11,12]$. When temperature above $25^{\circ} \mathrm{C}$ with high humidity and strong wind results decreased yield and for night temperatures above $20^{\circ} \mathrm{C}$ with high humidity and lack of sunshine result to poor fruit production and immoderate vegetative production [13].

With good drainage, tomatoes can bloom in different soil types but preferably in sandy to sandy loam soil. Optimum soil $\mathrm{pH}$ for tomato is 5.8-7.0. If soil $\mathrm{pH}$ is below 5.8 (soil is acidic), lime should be apply to the soil. New transplanted seedlings should water the plants regularly for 1-2 weeks and after seeding, when the soil gets dry, irrigation can be done usually 7-10 days' interval according to soil type and weather conditions [12]. Tomato must irrigate by furrow method during dry season. Accordingly, tomato is very sensitive in flood, thus, irrigation is done only to moisten root during the flowering up to the harvest [14]. The water requirements for the newly planted tomato in a day (7-10 days) must be a quart of water, more water if wind is notable, temperatures are hot, and if it is sunny. When tomato is planted on the ground for 10-14 days, over 10 days' water must be 1-3 inches or even 2 weeks. For main growing season, follow the 1-3 inches a week rule, for summer seasons, water the tomato from 2-3 times a week. When the soil type is sandy soil, 
water it consistently for 2-3 times a week and double the inch a week during growing season [15].

The ideal range of humidity for tomato ranges from $80 \%-90 \%$. The tomato loses weight and low quality when humidity less than $80 \%$ while it is considerable at risk of rot and mold growth when humidity is greater than $90 \%$ [16]. Wind causes pollination for tomato, because of unusual structure of tomato flower, wind is mainly help to shaken the pollen and make it fall to another anther causes reproduction of tomato [17]. High wind speed can result to high transpiration rates but it also depends on the available water in the soil. If soil moisture is very low, despite the high wind speed the plant leaves for some time will tend to withhold the water it has. In extreme cases such as long exposure to high wind speed drying of the leaves might occur.

- Chili - Chili is termed as "Sili" in the Philippines [18]. The ideal temperature must be $20^{\circ} \mathrm{C}-32^{\circ} \mathrm{C}$, but it will not set fruit when temperature at night is greater than $24^{\circ} \mathrm{C}$. If the temperature falls at $15^{\circ} \mathrm{C}$ or surpass to $32^{\circ} \mathrm{C}$ for long period, growth and production will reduced. The soil $\mathrm{pH}$ must range from 5.5 to 6.8 [19]. The optimal humidity for chili peppers must be $60 \%-70 \%$ [20]. For small plant, the amount of water for the chili must be 500 millilitres as it grows bigger, 0.5 soil moisture for day [21].

- Bell Pepper - Planting bell pepper in hot weather, and moist drained soil is best. Accordingly, to have a good germination, before planting the seeds it should be kept in warm and moist from $70^{\circ} \mathrm{F}-80^{\circ} \mathrm{F}$ [22]. For its temperature, it ranges for $18-27^{\circ} \mathrm{C}$, when the temperature decreased from $18^{\circ} \mathrm{C}$ below and increased to $27^{\circ} \mathrm{C}$ for long period, yield and growth will decrease. Bell peppers can endure up to $30^{\circ} \mathrm{C}$ day time temperature. Bell pepper is humidity insensitive; it means that humid doesn't affect its flowering or fruit set. The recommended soil type is sandy, loam or siltyloam because of its capability with water holding. Indeed, bell pepper can grow in different types of soil as long as its $\mathrm{pH}$ is 5.5-6.8 and the soil should well drain. If the bell pepper is planted during September-October, irrigations is not very necessary, but if it is planted during summer season, irrigation is needed; always water it especially the root and do not let the ground crack [23]. An approach for watering the Bell pepper is two to three times a week, with a water level of 0.1 to 0.2 [22].

An extreme temperature stunts the growth of these crops that eventually result to reduced yield. Most plants are more affected rather by the high temperature fluctuations or thermoperiodicity especially for tomato plants. 
The high temperature difference between day and night will affect the plant in the long term. DIF control (Differential temperature) affects the height of the plant, number of nodes and number of leaves. For tomatoes, it shows restricted stem elongation and small leaf area under negative DIF (cooler day than night).

Specifically, temperature controls the rate of photosynthesis, respiration, transpiration, translocation of materials and build-up of new cells. In general, an increase of $10^{\circ} \mathrm{C}$ in the environmental temperature results to a doubled rate of biochemical reactions controlled by enzymes. This generalization is true until an optimum temperature of the crop is reached. In addition, most crops seize to perform its physiological functions at $35^{\circ} \mathrm{C}$ due to disorganization of protein (this is based on Van Hoff Law). In case such that the plant reach permanent wilting point no action can revive the plant, since at this stage physiological processes such as respiration seize to function. There are many possible problems that might be encountered when growing these vegetables crops in terms of physiological, environmental, physical and chemical aspects. If these crops are planted during rainy seasons with high wind speed, wind modifications or protection strategies must be done to prevent chilling effect, and mechanical damages. During the vegetative stages of these vegetable crops, pests are the number one problem. Inadequate soil nutrients necessary for the crops growth can also be encountered therefore proper fertilizer application based on the relative amount in the soil and that needed by the crop must be properly assessed.

Vapor pressure difference is very crucial factor to consider when growing these crops. Tomatoes prefer low humidity while bell pepper requires high humidity. These humidity requirements depend on the physical characteristics of the plants' leaves. The change in the humidity causes changes in the transpiration rate of the crops. To prevent crop diseases such as blossom end rot for tomatoes, the humidity of the surrounding environment as affected by the evaporation should be optimum. This should allow normal transpiration rates in order for the plants to take in the right number of nutrients it requires for proper functioning. As much as possible, high transpiration rates should not be kept for longer time since it would eventually result to plant having leaf tip burn.

Since plants are very dependent on moisture just like sunlight and carbon dioxide; it is a basic necessity for plant growth. These plants required moisture in order to bring the nutrients from the soil to the leaves and also in order to create its required ATPs (energy) for its proper physiological functioning. If the soil lacks water up to permanent wilting point, the plant will die. 
Table 1 USL and LSL standard values

\begin{tabular}{lccc}
\hline \multirow{3}{*}{ Plant } & \multicolumn{3}{c}{ USL and LSL Value } \\
\cline { 2 - 4 } Tomato & Parameter & USL & LSL \\
& Temperature & $30^{\circ} \mathrm{C}$ & $20^{\circ} \mathrm{C}$ \\
& Humidity & $90 \%$ & $80 \%$ \\
& Soil Moisture & $0.3 \mathrm{~mL}$ & $0.1 \mathrm{~mL}$ \\
& Soil Acidity & $7.0 \mathrm{pH}$ & $5.8 \mathrm{pH}$ \\
\hline Tomato 2 & Temperature & $30^{\circ} \mathrm{C}$ & $20^{\circ} \mathrm{C}$ \\
& Humidity & $90 \%$ & $80 \%$ \\
\hline Chili & Temperature & $32^{\circ} \mathrm{C}$ & $20^{\circ} \mathrm{C}$ \\
& Humidity & $70 \%$ & $60 \%$ \\
& Soil Moisture & $0.5 \mathrm{~mL}$ & $0.2 \mathrm{~mL}$ \\
& Soil Acidity & $6.8 \mathrm{pH}$ & $5.5 \mathrm{pH}$ \\
\hline Bell Pepper & Temperature & $27^{\circ} \mathrm{C}$ & $18^{\circ} \mathrm{C}$ \\
& Humidity & $\mathrm{N} / \mathrm{A}$ & $\mathrm{N} / \mathrm{A}$ \\
& Soil Moisture & 0.2 & 0.1 \\
& Soil Acidity & $6.8 \mathrm{pH}$ & $5.5 \mathrm{pH}$ \\
\hline
\end{tabular}

\subsection{Proposed Design}

In this study, SPC-Based Decision Supporting for Data Analysis of Tomato, Bell pepper and Chili is to be developed by the proponents. The study is just a part of a whole SMART Farm. The system focuses more on the analysis and

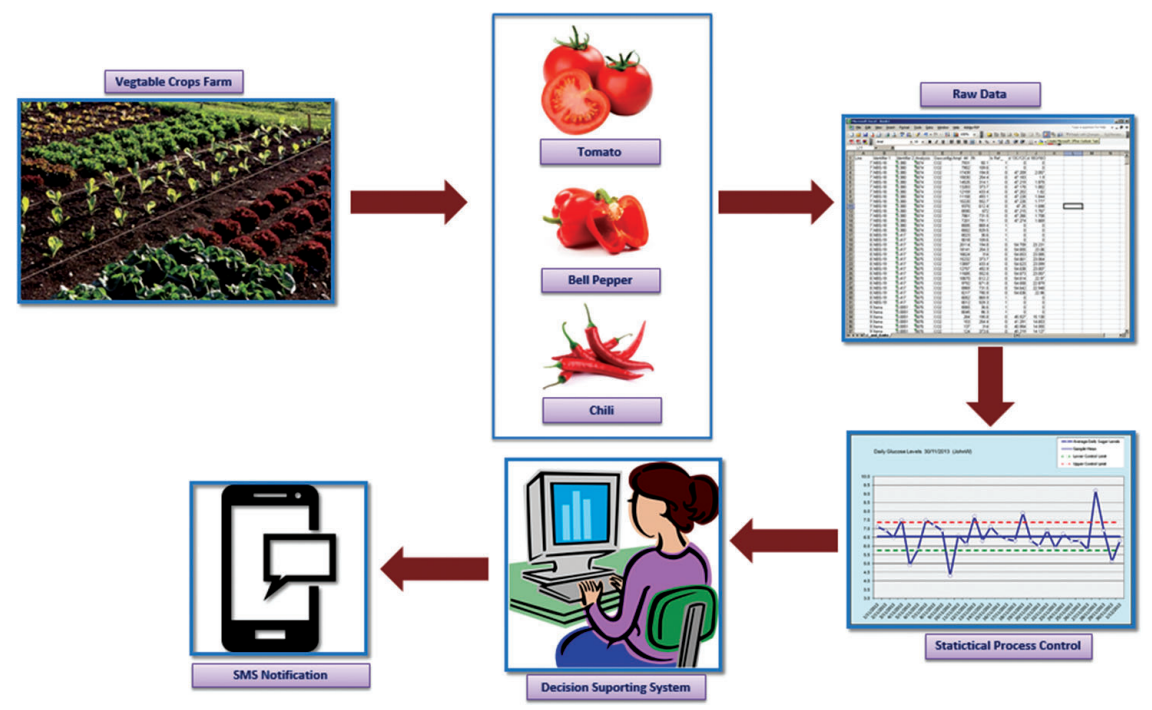

Figure 9 Structural design of the system. 
interpretation of data which will be provided by the people who managed the monitoring system. This means that the system is linked to the other systems and independent to the monitoring system, because data will be coming form the people who monitors the plant and its parameter. The user will be given an excel file from the other group, to be placed in the system. The file contains monitored data of the vegetable crops with respect to its observed parameter. The system will read the file and to be plotted in a chart with the given Upper and Lower Control Limit in showing trends and variations as well as the constraints data. The system will analyze the detected problem by the used of Statistical Process Control (Control Charts) and make decision based on the data whether it encounters an OOC or an OOS. After analyzing data, the system will provide a notification to be sent through SMS containing the abnormalities that were detected in the data.

\subsection{Design Consideration}

The Figure 10 will be the smartphone which will be used in sending SMS. The Figure 11, LCD Monitor will be where the chart will be displayed.

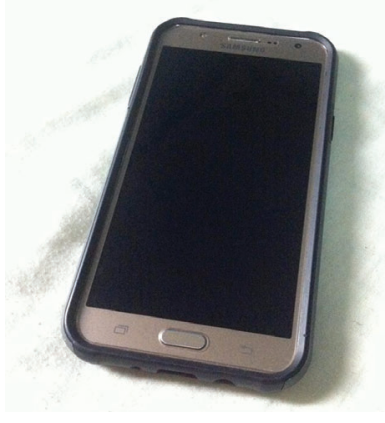

Figure 10 Smarthphone.

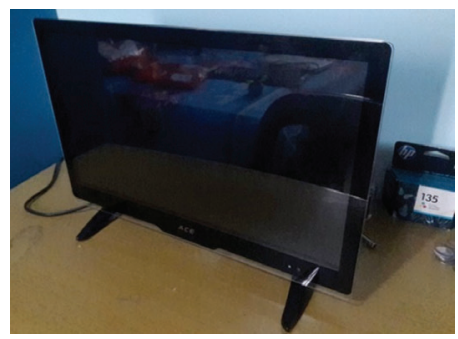

Figure 11 LCD monitor. 


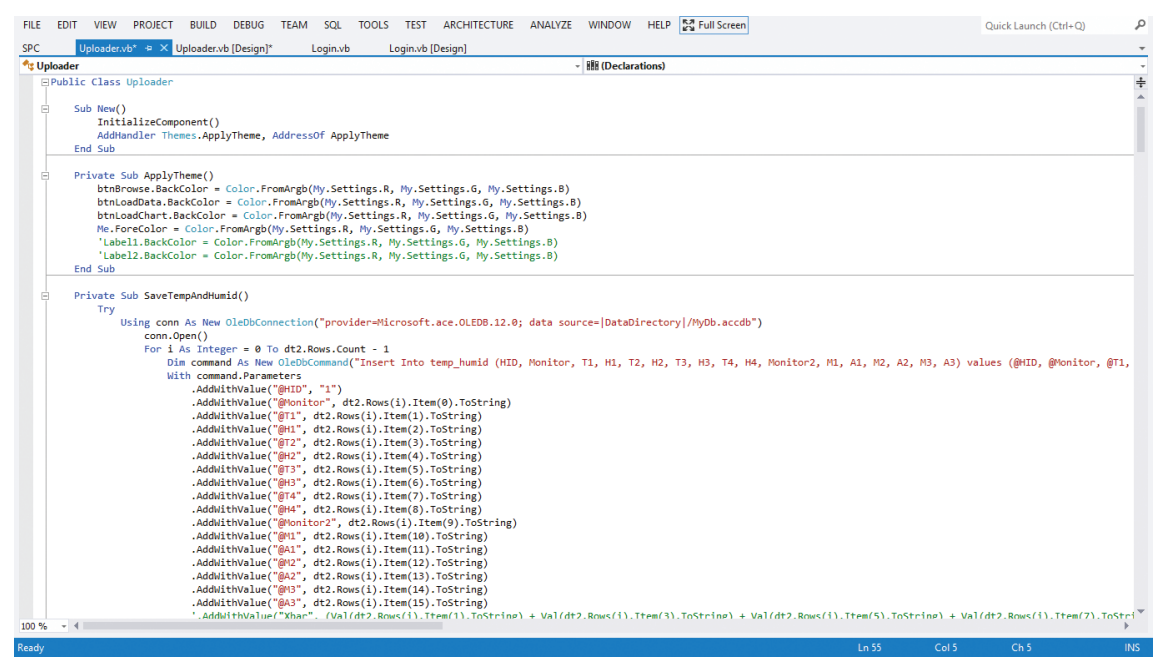

Figure 12 Sample codes.

The Figure 12, some parts of the Code, is used by the proponents in developing the system.

\section{Results and Analysis}

Table 2 depicts the results between the Experimental and Theoretical value, and based on the data, all of the percentage error value gives $0 \%$. The percentage error calculation was used in testing the accuracy in getting the right result of the system. Thus, through the answers, it shows that the system is functional and gives accurate results.

$$
\% \text { error }=\frac{\text { Theoretical Value }- \text { Experimental Value }}{\text { Theoretical Value }}
$$

Table 3 shows the results between the Experimental and Theoretical value, and based on the data, all of the percentage error value gives $0 \%$. The percentage error calculation was used in testing the accuracy in getting the right result of the system. Thus, through the answers, it shows that the system is functional and gives accurate results.

Table 4 shows the results between the Experimental and Theoretical value, and based on the data, all of the percentage error value gives $0 \%$. The percentage error calculation was used in testing the accuracy in getting the result in the system. Thus, through the answers, it shows that the system is functional and gives accurate results. 
SPC-Based Decision Supporting System for Data Analysis

Table 2 Comparison of UCL for 1st testing of data

\begin{tabular}{lcccc}
\hline \multirow{3}{*}{ Plant } & \multicolumn{4}{c}{ UCL } \\
\cline { 2 - 5 } Tomato & Parameter & Experimental & Theoretical & $\%$ Error \\
& Temperature & 39.6486 & 39.6486 & $0 \%$ \\
& Soil Moisture & 0.628 & 0.628 & $0 \%$ \\
& Soil Acidity & 10.3492 & 10.3492 & $0 \%$ \\
\hline Tomato & Temperature & 35.1394 & 35.1394 & $0 \%$ \\
& Humidity & 0.8606 & 0.8606 & $0 \%$ \\
\hline Chili & Temperature & 39.6486 & 39.6486 & $0 \%$ \\
& Humidity & 1.0846 & 1.0846 & $0 \%$ \\
& Soil Moisture & 0.628 & 0.628 & $0 \%$ \\
& Soil Acidity & 10.3492 & 10.3492 & $0 \%$ \\
\hline Bell Pepper & Temperature & 35.1394 & 35.1394 & $0 \%$ \\
& Humidity & 0.8606 & 0.8606 & $0 \%$ \\
& Soil Moisture & 0.628 & 0.628 & $0 \%$ \\
& Soil Acidity & 10.3492 & 10.3492 & $0 \%$ \\
\hline
\end{tabular}

Legend: Experimental Value - computation was made by the system.

Theoretical Value - computation was made using manual calculation.

Table 3 Comparison of CL for 1st testing of data

\begin{tabular}{lcccc}
\hline \multirow{2}{*}{ Plant } & \multicolumn{3}{c}{ CL } \\
\cline { 2 - 5 } Tomato & Parameter & Experimental & Theoretical & $\%$ Error \\
& Temperature & 24.42 & 24.42 & $0 \%$ \\
& Soil Moisture & 0.22 & 0.22 & $0 \%$ \\
& Soil Acidity & 6.31 & 6.31 & $0 \%$ \\
\hline Tomato & Temperature & 31.6 & 31.6 & $0 \%$ \\
& Humidity & 0.83 & 0.83 & $0 \%$ \\
\hline Chili & Temperature & 24.42 & 24.42 & $0 \%$ \\
& Humidity & 0.85 & 0.85 & $0 \%$ \\
& Soil Moisture & 0.22 & 0.22 & $0 \%$ \\
& Soil Acidity & 6.31 & 6.31 & $0 \%$ \\
\hline Bell Pepper & Temperature & 31.6 & 31.6 & $0 \%$ \\
& Humidity & 0.83 & 0.83 & $0 \%$ \\
& Soil Moisture & 0.22 & 0.22 & $0 \%$ \\
& Soil Acidity & 6.31 & 6.31 & $0 \%$ \\
\hline
\end{tabular}

Legend: Experimental Value - was computed by the system.

Theoretical Value - was computed using manual calculation.

Table 5 depicts the results between the Experimental and Theoretical value, and based on the data, all of the percentage error value gives $0 \%$. The percentage error calculation was used in testing the accuracy in getting the result in the system. Thus, through the answers, it shows that the system is functional and gives accurate results. 
Table 4 Comparison of LCL for 1st testing of data

\begin{tabular}{lcccc}
\hline \multirow{2}{*}{ Plant } & \multicolumn{4}{c}{ LCL } \\
\cline { 2 - 5 } Tomato & Parameter & Experimental & Theoretical & $\%$ Error \\
& Temperature & 9.1914 & 9.1914 & $0 \%$ \\
& Soil Moisture & -0.188 & -0.188 & $0 \%$ \\
& Soil Acidity & 2.2708 & 2.2708 & $0 \%$ \\
\hline Tomato & Temperature & 28.0606 & 28.0606 & $0 \%$ \\
& Humidity & 0.7994 & 0.7994 & $0 \%$ \\
\hline Chili & Temperature & 9.1914 & 9.1914 & $0 \%$ \\
& Humidity & 0.6154 & 0.6154 & $0 \%$ \\
& Soil Moisture & -0.188 & -0.188 & $0 \%$ \\
& Soil Acidity & 2.2708 & 2.2708 & $0 \%$ \\
\hline Bell Pepper & Temperature & 28.0606 & 28.0606 & $0 \%$ \\
& Humidity & 0.7994 & 0.7994 & $0 \%$ \\
& Soil Moisture & 0.22 & 0.22 & $0 \%$ \\
\hline
\end{tabular}

Legend: Experimental Value - was computed by the system.

Theoretical Value - was computed using manual calculation.

Table 5 Comparison of range bar for 1st testing of data

\begin{tabular}{lcccc}
\hline \multirow{3}{*}{ Plant } & \multicolumn{4}{c}{ Range Bar } \\
\cline { 2 - 5 } Tomato & Parameter & Experimental & Theoretical & $\%$ Error \\
& Temperature & 14.93 & 14.93 & $0 \%$ \\
& Soil Moisture & 0.4 & 0.4 & $0 \%$ \\
& Soil Acidity & 3.96 & 3.96 & $0 \%$ \\
\hline Tomato & Temperature & 3.47 & 3.47 & $0 \%$ \\
& Humidity & 0.03 & 0.03 & $0 \%$ \\
\hline Chili & Temperature & 14.93 & 14.93 & $0 \%$ \\
& Humidity & 0.23 & 0.23 & $0 \%$ \\
& Soil Moisture & 0.4 & 0.4 & $0 \%$ \\
& Soil Acidity & 3.96 & 3.96 & $0 \%$ \\
\hline Bell Pepper & Temperature & 3.47 & 3.47 & $0 \%$ \\
& Humidity & 0.03 & 0.03 & $0 \%$ \\
& Soil Moisture & 0.4 & 0.4 & $0 \%$ \\
& Soil Acidity & 3.96 & 3.96 & $0 \%$ \\
\hline
\end{tabular}

Legend: Experimental Value - was computed by the system.

Theoretical Value - was computed using manual calculation.

The Figure 13, 14 shows the comparison between the data that was used to run in Minitab 17, software for Statistical Process Control and data which was run using the computation set in the system. The data of Temperature-Tomato was uploaded in the system. The Figure 13 shows that the system is capable of producing charts which contains the exact and similar position and value 


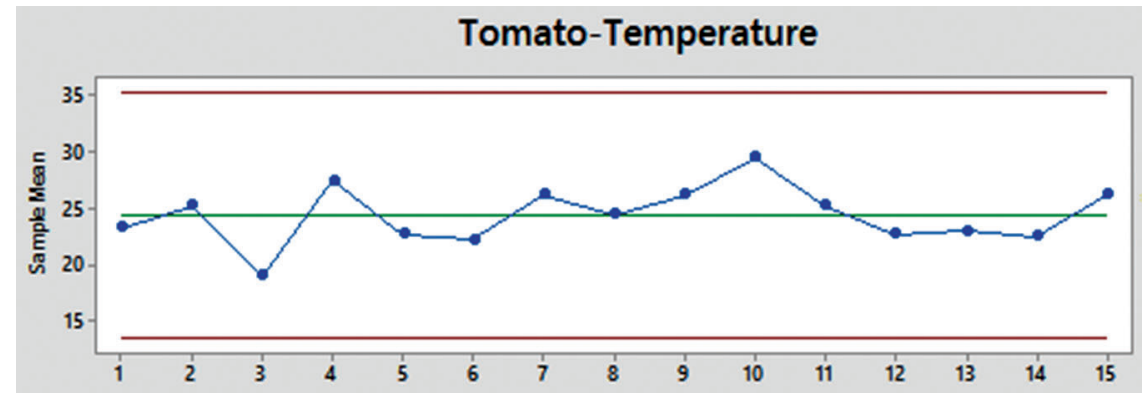

Figure 13 Plot of data for Tomato-Temperature using Minitab 17.

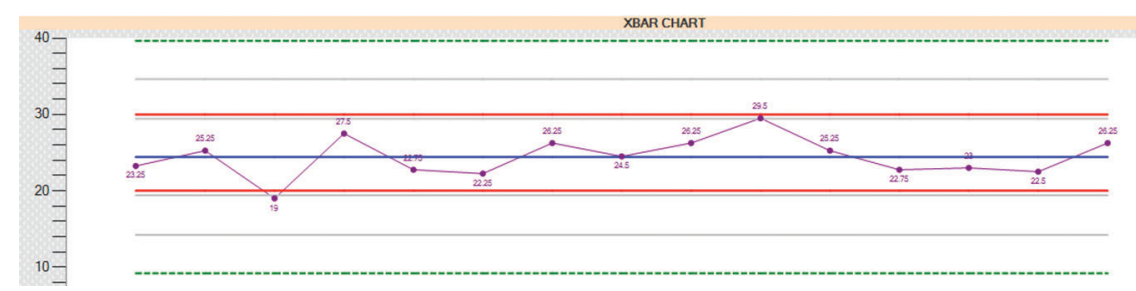

Figure 14 Plot of data for Tomato-Temperature in the system.

as Figure 14. Additionally, through the observation in Figure 13 which has a USL and LSL line, a data falls outside the USL and LSL, this means that the system detected an OOS pattern. The Figure 15 shows that when a point falls outside the USL or LSL, an OOS pattern, this means that a message will be sent to the user; that is what Figure 13 is showing. A pattern of abnormality was detected in data point 3 which shows an OOS. The Figure 13, 14 and 15 shows the functionality of the system. The system generates an accurate graph and was able to send message based the result analyzed using SPC theory.

\section{Summary, Conclusions and Future Directives}

\subsection{Summary}

The study entitled "SPC-Based Decision Supporting System for Data Analysis of Tomato, Bell Pepper and Chili" was developed using Visual Studio software and VB.Net programming language as well as the Statistical Process Control theory that was applied in determining the occurrences found in the data/chart. The system is linked to the other group such as monitoring system because the data that was uploaded in the system was from the group who monitored 

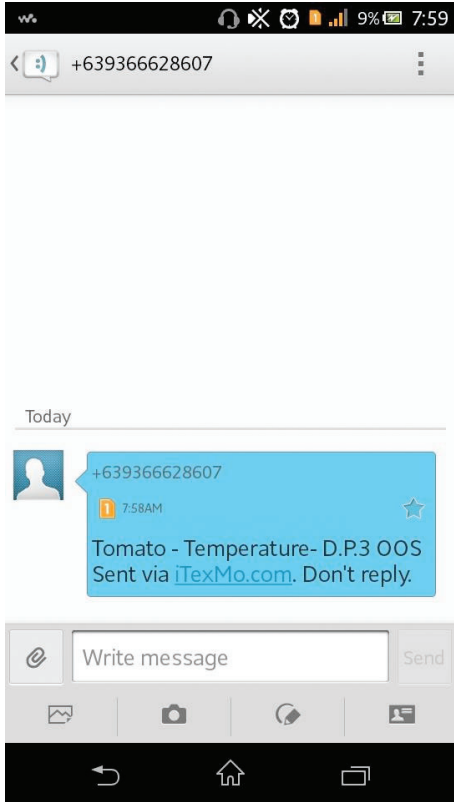

Figure 15 Text message for Tomato-Temperature.

the vegetable crops which will be given to the researchers. Using Decision support system, the proponents were able to detect the whether the pattern is an OOS or an OOC; with these, the proponents were able to find the precise. The detected behavior/occurrences were sent via SMS, it shows whether it is an OOC or an OOS. The developed system can also be used in adding or deleting an account, and changing password. Also, several tests were conducted to test the accuracy and functionality of the system that could satisfy the objectives of the study, and the accuracy of the system was tested using the percentage error.

\subsection{Conclusions}

After dealing with series of testing the proponents can conclude that the authorized person can be informed by the system whether an abnormality was detected.

- The proponents meet the requirements of displaying the chart in the LCD monitor and were able to create a system which enables to read an Excel File with the data from monitored vegetable crops such Tomato, Chinese 
cabbage and Bell Pepper containing the different used parameters like Temperature, Humidity, Soil Moisture and pH Level.

- The proponents were able to detect patterns in the chart using Decision Support System and determine whether it is an OOC or OOS.

- The system was able to send message with which contains the abnormalities detected in the data.

- The proponents tested the functionality and accuracy and of the system observation. The proponents used percentage error in getting the accuracy of the system. After the development of software and hardware components of the system. The proponents have the opportunity to test the system's functionality and accuracy. After dealing with series of testing, the system's functionality is proven capable monitoring abnormalities of data. The system generates an accurate graph and was able to send message based the result analyzed using SPC theory.

\subsection{Future Directives}

The proponents recommend to the future researchers the followings:

1. Future researchers can use different programming language (Java, MySQL, etc.) for additional function and features.

2. The researches would like to suggest the use sensors to make it real time.

3. The researchers would like to recommend on exploring and adding more patterns of behaviors of data.

4. The future researchers may also include in the SMS notification the possible actions needed by the plants.

\section{References}

[1] Basalla, G. (1989). The Evolution of Technology. Cambridge: Cambridge University Press.

[2] Design and Implementation of a Computerized Farm Management Information System (A Case Study of a Piggery Farm). Available at: http:// classgist.com/projectdetails.aspx ?id=79 [accessed April 23, 2016].

[3] Vidanapathirana, N. P. (2016). Agricultural Information Systems and Their Applications for Development of Agriculture and a Rural Community, a Review Study. Available at: https://www.academia.edu/298 0504/Agricultural_information_systems_and_their_applications_for_deve lopment_of_agriculture_and_rural_community_a_review_study [accessed April 23, 2016]. 
[4] Agriculture Available at: Available at: http://pinas.dlsu.edu.ph/gov/agricu lture.html [accessed April 23, 2026].

[5] Philippines - Agriculture. Available at: http://www.nationsencyclo pedia.com/economies/Asia-and-the-Pacific/Philippines-AGRICULTUR E.html [accessed April 23, 2016].

[6] Statistical Process Control. Available at: https://www.moresteam.com/ toolbox/statistical-process-control-spc.cfm [accessed May 02, 2016].

[7] Statistical Process Control. Available at: http://castle.eiu.edu/ pingliu/int 4843/resources/Control_chart.htm [accessed May 02, 2016].

[8] Burton, V. L. (ed.). (2011). Encyclopedia of Small Business III. Vol. 1, 4th Edn. Detroit: Gale, Cengage Learning.

[9] Encyclopedia of Management, 6th Edn. Detroit: Gale, Cengage Learning.

[10] Tomato Plants. Available at: http://www.food.com/about/tomato-151 [accessed May 04, 2016].

[11] Tomato Plants. Available at: http://www.eastwestseed.com/philippines/ en/products/crop-managment.php?man=ph_en_maTomato [accessed May 04, 2016].

[12] Tomato Plants. Available at: http://www.fao.org/nr/water/cropinfo tomato.html [accessed May 04, 2016].

[13] Manzano, V. J. P. Jr., and Mizoguchi, M. (2016). Field Monitoring System and Analysis of Rainfall Data for Tomato Cropping Calendar in Batac City, Ilocos Norte, Philippines. Available at: http://www.pssnon line.org/wp-content/uploads/2013/08/11-17-Manzano-Mizoguchi.pdf [accessed May 04, 2016].

[14] Tomato Plant. Available at: http://www.pinoybisnes.com/agri-business/ tomato-production-guide/ [accessed May 04, 2016].

[15] Tomato Plant. Available at: http://www.tomatodirt.com/wateringtomatoes-faqs.html [accessed May 04, 2016].

[16] Tomato.Available at: http://www.tis-gdv.de/tis_e/ware/gemuese/tomaten/ tomaten.htm\#feuchte [accessed May 04, 2016].

[17] Tomato. Available at: http://ecop.pbworks.com/w/page/40489664/Tomat oes\%20Grown\%20Upside\%20Down [accessed May 04, 2016].

[18] Chili Peppers. Available at: http://philfoodie.blogspot.com/2011/06/siliphilippine-chilies.html [accessed May 05, 2016].

[19] Hot Chili Peppers. Available at: http://203.64.245.61/web_crops/pepper/ chili_pepper.pdf [accessed May 05, 206].

[20] Hot Chili Peppers. Available at: http://www.engineeringtoolbox.com/ fruits-vegetables-storage-conditions-d_710.html [accessed May 05, 2016]. 
[21] Hot Chili Peppers. Available at: http://www.karrimah.com.au/Growing Chillies.html [accessed May 05, 2016].

[22] Bell Pepper. Available at: http://www.vegetablegardener.com/item/2655/ how-to-grow-bell-peppers/page/all [accessed May 06, 2016].

[23] Bell Pepper. Available at: http://203.64.245.61/fulltext_pdf/E/20012005/e03420.pdf [accessed May 06, 2016].

\section{Biographies}

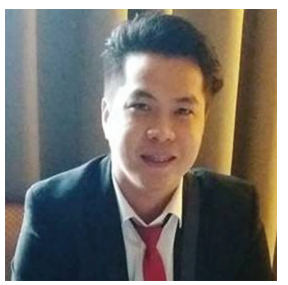

Rionel Belen Caldo received his Bachelor's Degree in Computer Engineering from Lyceum of the Philippines University - Laguna (LPU-L) in 2006, Masters in Public Administration (MPA) in Polytechnic University of the Philippines in 2010, and Masters of Science in Electronics and Engineering (M.Sc. - ECE) in De La Salle University in 2013 under Department of Science and Technology (DOST) Engineering Research and Development Technology (ERDT) scholarship. Currently, he is pursuing his Masters in Engineering with specialization in Computer Engineering in Adamson University under Commission on Higher Education (CHED) scholarship program. He also pursues his Doctor of Philosophy in Electronics and Communications Engineering (Ph.D. - ECE) under DLSU scholarship. He worked as Statistical Process Control (SPC) Data Management System (DMS) Engineer for three years in Ibiden Philippines, Inc. He took full time faculty position in LPULaguna. He also handled Intellectual Property Coordinator position, Research Coordinator of COECS Department and Computer Engineering Program Chair in the same institution. Currently, he is an Assistant Professorial Lecturer 2 in De La Salle University, Assistant Professor 3 in Mapua University at Laguna, Assistant Professor 4 in University of Perpetual Help Dalta System Calamba Campus and Instructor 1 in Tanauan City College. Ergo, he is the CEO/President/Project Manager of R.CALDO Technical Consultancy Services founded March 19, 2017. He was able to present and publish multiple papers in the local and international arena, including Scopus, EI and ISI publications in respected journals. 


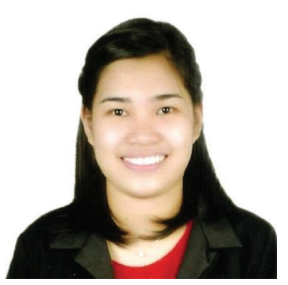

Zaira Caranay took up Bachelor of Science in Computer Engineering at Lyceum of the Philippines University - Laguna (LPU-L), an Engineer in a manufacturing company. She was awarded as the Top 1 Overall Computer Engineering Student for 1st Semester last school year 2016-2017 and last October 2016 she was able to present three papers and received an award for being the 1st Best Presenter in the 2nd Research Conference on Computer Engineering Applications held at LPU-L. She was also able to present a paper in International Grand Challenge Engineering Research Conference (6th eureca) at Taylor's University, Lakeside Campus, Kuala Lumpur, Malaysia last July 2016 and awarded as Top 8 Computer Engineering Student for 2nd Semester (S.Y. 2015-2016) last July 2016. She also became a part of a student leader organization, elected as an Auditor for the S.Y. 2014-2015 and Secretary for S.Y. 2015-2016 in LyCo-CpE (Lyceans' Coalition of Computer Engineers). 